Portland State University

PDXScholar

8-21-1987

\title{
Decrease in Selected Temperature After Intracranial Dopamine Injections in Goldfish
}

Hercules Theodore Panayiotides-Djaferis

Portland State University

Follow this and additional works at: https://pdxscholar.library.pdx.edu/open_access_etds

Part of the Biology Commons, and the Physiology Commons

Let us know how access to this document benefits you.

\section{Recommended Citation}

Panayiotides-Djaferis, Hercules Theodore, "Decrease in Selected Temperature After Intracranial Dopamine Injections in Goldfish" (1987). Dissertations and Theses. Paper 3733.

https://doi.org/10.15760/etd.5617

This Thesis is brought to you for free and open access. It has been accepted for inclusion in Dissertations and Theses by an authorized administrator of PDXScholar. Please contact us if we can make this document more accessible: pdxscholar@pdx.edu. 
AN ABSTRACT OF THE THESIS OF Hercules Theodore PanayiotidesDjaferis for the Master of Science in Biology presented August 21, 1987 .

Title: Decrease in selected temperature after intracranial dopamine injections in goldfish.

APPROVED BY MEMBERS OF THE THESIS COMMITTEE:
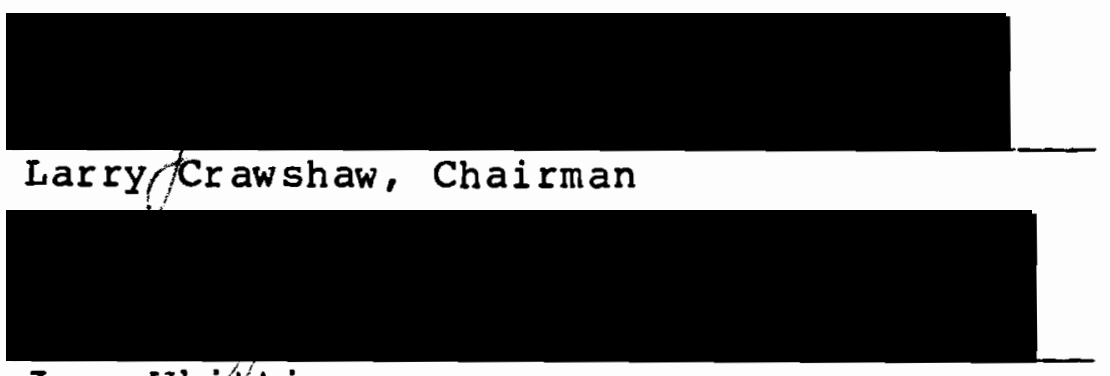

Joan Whittier

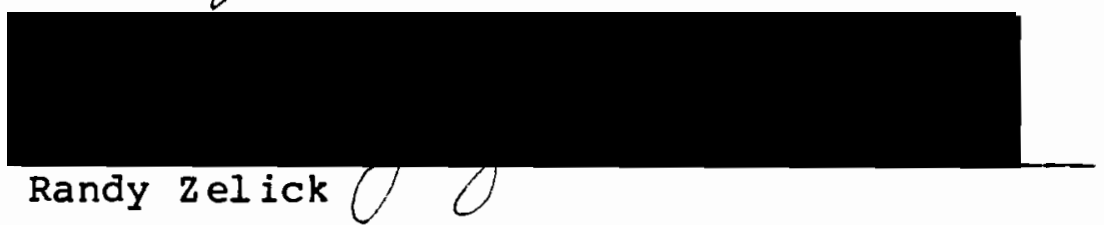

Goldfish (Carassius auratus) $(40-80 \mathrm{~g})$ were injected with dopamine into the forebrain to study the possible involvement of this amine in central temperature regulation in these fish. Dopamine caused a decrease in selected temperature after injection into the rostral nucleus preopticus periventricularis (NPP). This effect was dependent on the dose of dopamine administered. Doses of $25,50,100$ and $250 \mathrm{ng}$ were used, injected in a volume of 
0.2ul. Injections in regions adjacent to the NPP elicited hypothermic effects only at the higher dosages. These effects were not consistent. Injections in caudal regions of the NPP elicited no effect. The effects of dopamine were blocked by haloperidol, a selective antagonist of dopamine. It is suggested that dopamine acts on central thermoregulatory neurons, present in the rostral NPP, in the mediation of thermoregulatory behavior. Further, it is suggested that this action is mediated via dopaminergic receptors. 


\title{
DECREASE IN SELECTED TEMPERATURE AFTER INTRACRANIAL DOPAMINE INJECTIONS IN GOLDEISH
}

\author{
by \\ HERCULES THEODORE PANAYIOTIDES-DJAFERIS
}
A thesis submitted in partial fulfillment of the requirements for the degree of
MASTER OF SCIENCE
in
BIOLOGY

Portland State University

1987 
TO THE OFFICE OF GRADUATE STUDIES AND RESEARCH:

The members of the Committee approve the thesis of Hercules Theodore Panayiotides-Djaferis presented August 2I, 1987.

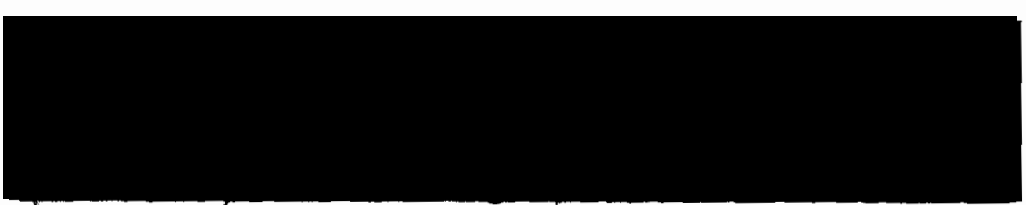

Larry Cfawshaw, Chairman
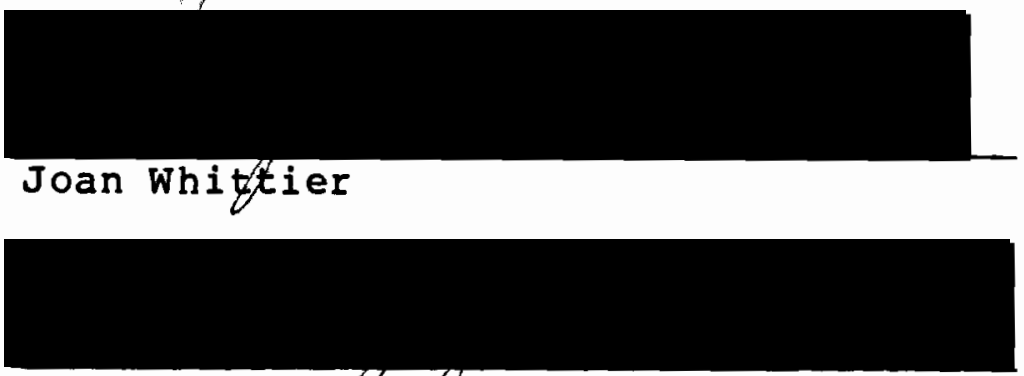

Randy zelick $O$

\section{APPROVED :}

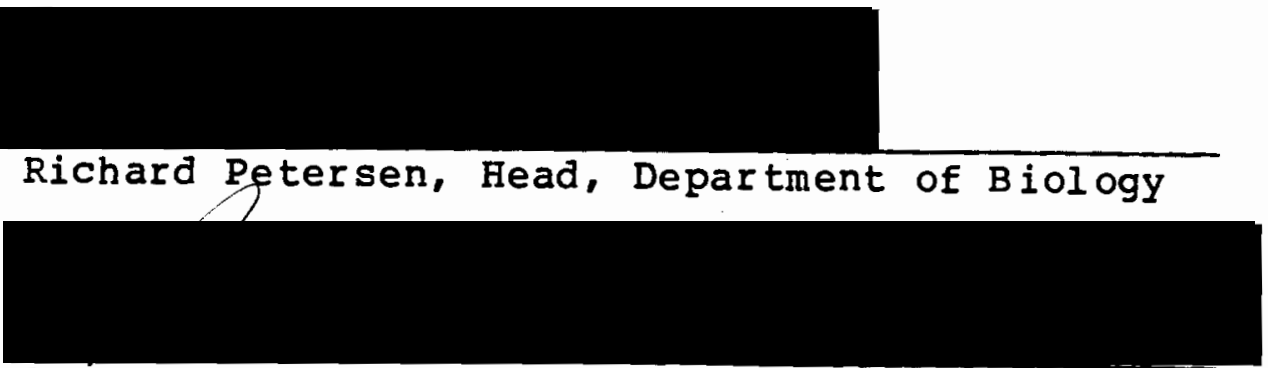

Bernard Ross, Vice Provost for Graduate Studies 


\section{ACKNOWLEDG EMENTS}

It is a pleasure to thank Dr. Larry Crawshaw who provided not only guidance and helpful criticism for this work but also a scholarly and yet relaxed environment in which to work.

Special thanks are due to Lonnie Wollmuth who offered substantial and sacrificial help both in the execution of the experimental work and in the preparation of this manuscript. However, I would also like to thank him for offering me an introduction to what must be the epitome of American sports - baseball.

Drs. Joan Whittier, Randy zelick and Alfred Levinson are sincerely thanked for their thoroughness in studying the manuscript and making helpful suggestions. Dr. Whittier's help in the statistical analysis of the data is especially appreciated.

It has been enjoyable to work around Candace o'Connor and Rick Rausch. The help of Wayne Palioca is appreciated. The understanding and support of my wife, Susie, made it possible to complete this work successfully.

The author lastly acknowledges the Creator to whom only belongs praise, glory and honor. 
TABLE OF CONTENTS

PAGE

ACKNOWLEDGEMENTS • • • • • • • • • • • • • • • •

i i i

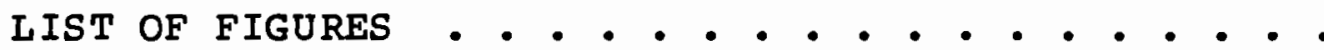

v

\section{CHAPTER}

I LITERATURE REVIEW. - . . . . . . . . . . .

II INTRODUCTION - . . . . . . . . . . .

Surgical procedure . . . . . . . .

Temperature selection measurements. •

Intracranial injections . . . . . . 18

Histology . . . . . . . . . . . 19

Data analysis... . . . . . . . 20

IV RESULTS • • • • • • • • • • • • • • • 22

V DISCUSSION . • • . . . . • . . . . . 26

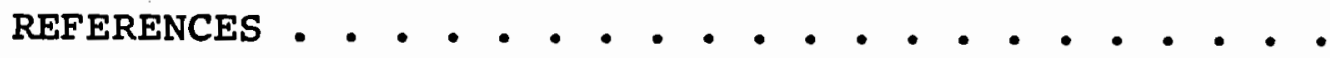




\section{LIST OF FIGURES}

FIGURE

PAGE

1. A Neuronal Model for the Regulation of Body Temperature by Activation of Behavioral Responses. . . . . . . . . .

2. Pre- and Post-injection selected Temperature (at 2 minute intervals) for Injections into the Rostral Nucleus Preopticus Periventricularis (NPP) . . . . . . . . . . . . .

3. A Semi-logarithmic Dose-response Curve for Dopamine Injections into the Rostral NPP . . 
CHAPTER I

\section{LITERATURE REVIEW}

Animals, both vertebrate and invertebrate, show preferences for a particular body temperature and they will act to maintain their body temperature at that particular level. This can be seen even among the simplest animals, the protozoa, where paramecia were shown by Mendelsohn in 1895 (cited in Hammel et al., 1973) to congregate in a narrow temperature interval within a 1 inear thermal gradient. If this temperature interval was moved anywhere along the thermal gradient the paramecia migrated with it.

Animals can be divided into two groups depending on the way they maintain the desired body temperature. Generally, fish, amphibians, reptiles and invertebrates regulate body temperature through behavioral means, that is, by selecting a part of their environment which has the appropriate temperature. Animals whose body temperature equilibrates with the environmental temperature are called ectotherms, since they depend on external sources of heat to maintain the desired body temperature. Birds and mammals, on the other hand, possess additional physiological mechanisms that help them to maintain the desired body temperature regardless of the environmental temperature. Such 
mechanisms include cutaneous vasodilation, panting and sweating for losing heat and piloerection, vasoconstriction and shivering for conserving and producing heat. Since these organisms have internal mechanisms for generating heat and maintaining body temperature they are termed endotherms. In order to be able to regulate body temperature, it is necessary that the animal be able to sense its own body temperature. Having done this, the organism must activate the appropriate signals to effectors in order to correct any deviations from the desired body temperature. This presumably is what is happening with a paramecium when it selects a particular environmental temperature.

In vertebrates the nervous system mediates these actions. Neurons have been described within the brain of cats which alter their rate of firing in response to local heating (These are specifically thermosensitive cells since not all neurons tested responded in this way; Nakayama et al., 1961) and peripheral heating (Landgren, 1970). Neurons responding to cooling and heating have also been described within the hypothalamus of the green sunfish (Nelson and Prosser, 1981). Ambient temperature and core body temperature are seen in this way to be transduced into a neural signal. That these temperatures, once they are transduced, can be a basis for the activation of thermoregulatory behavior has been shown for both ectotherms and endotherms. Hammel et al. (1973) found that cooling 
the brain of an arctic sculpin inhibited the fish from avoiding water of an undesirably high temperature. Warming the brain caused the fish to spend less time in the hot environment as compared to fish where the brain was not warmed. In endotherms, heating or cooling the hypothalamus can lead to alterations in all thermoregulatory responses (Hammel, 1968).

Since the organism receives inputs on the temperature of its body and that of the environment and then reacts in an appropriate way to these inputs, it is likely that a neuronal circuit is present which integrates inputs and activates effectors appropriately. This circuit, in vertebrates, most likely involves the hypothalamus. In support of this assertion is the finding that the preoptic area of the hypothalamus of many mammals is the only part of the nervous system whose temperature, if shifted only 1-2 C above or below the normal, can lead to activation of heat loss or heat gain mechanisms respectively (Hammel, 1968). Animals for which this is true are the dog, cat, rabbit, rat, ox, goat and baboon (Hammel, 1968). Also, if the afferent neural connections to this part of the brain are destroyed by ablating the region dorsal to the hypothalamus the animal can maintain its normal body temperature under cold stress and will only slightly increase its temperature under heat stress (Hammel, 1968). This further suggests that the hypothalamic temperature, when transduced into 
neural activity, can be used to aid in the regulation of body temperature. Neural input into the preoptic area is, however, needed for normal, precise thermoregulation (Hammel, 1968).

Nelson and Prosser (1979) have shown that when the preoptic area of the brain of sunfish and goldfish is destroyed, these animals can no longer regulate their body temperature. Body temperature in the lesioned goldfish fluctuated by as much as $20 \mathrm{C}$ whereas in intact animals it only fluctuated by about 3-5 C. These findings therefore lend support to the assertion that the preoptic area/ anterior hypothalamus are very important structures for temperature regulation in the goldfish.

Neural information coming to the controlling centers from thermosensitive units around the body and within the hypothalamus is integrated and leads to the activation of thermoregulatory mechanisms to maintain core body temperature before it drops below or rises above normal. This is supported by the following evidence: The hypothalamic temperature of several endotherms, studied in a thermally neutral environment, has shown a natural fluctuation of $0.5-1 \mathrm{C}$ with no ensuing activation of thermoregulatory responses. Also, the mean hypothalamic temperature and its variability is not dependent on the environmental temperature even though the animal may be activating heat gain or loss mechanisms under thermal stress 
(Hammel, 1968). Further support is leant by the finding mentioned above that neural input into the preoptic area is required for normal thermoregulation.

The neural wiring of the controlling centers and the connections of the afferents with the centers are only partially understood (Crawshaw et al., 1985) . However, models have been put forward to account for the function of the controlling center and the body temperature regulator as a whole. Such a model is one proposed by Hammel (in Hammel et al. , 1973).

One approach which has been used in an attempt to elucidate the function of the important centers has been to inject substances with neuropharmacological properties into the brain and to study their effects on body temperature and thermoregulatory effectors. Since nerve cells communicate with each other by releasing chemicals called neurotransmitters, then it should be possible to mimic the action of the nervous system by applying putative neurotransmitter substances exogenously to the part of the nervous system in question. By studying the effects of the drugs on the thermoregulatory behavior of the animal, inferences can be made about whether the drug being used is one mediating thermoregulatory behavior in the intact animal. Once thermoregulatory effects are observed it does not, of course, "prove" that this drug plays a physiological role. Further corroborative evidence would be needed such 


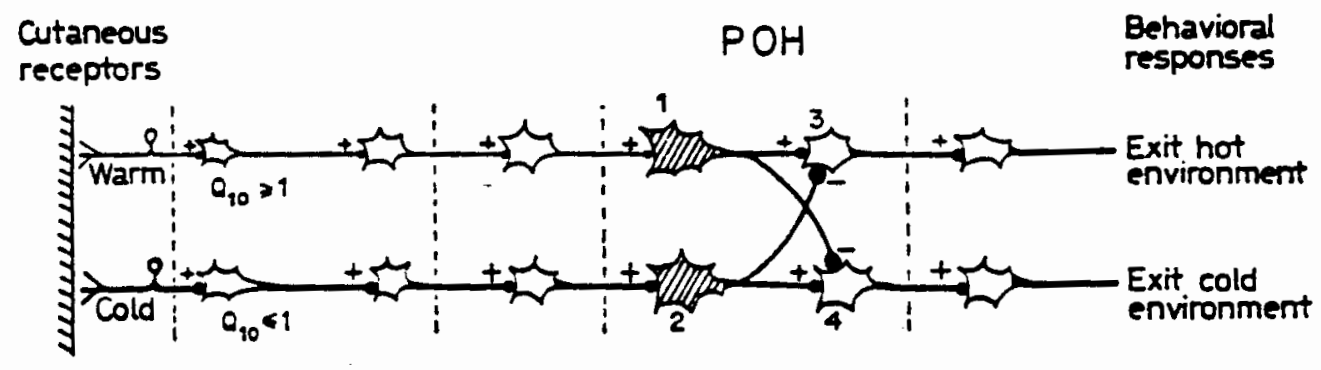

Figure 1. A neuronal model for the regulation of body temperature by activation of behavioral responses. POH: preoptic and hypothalamic nuclei. 1: a neuron which shows an increase in activity with increasing temperature. 2: a neuron which exhibits little temperature dependence or possibly a $Q_{10}$ of less than 1 . From Hammel et al., (1973) 
as the presence of this substance in the area in question and whether it is found in and released from presynaptic cells. Evidence would also be needed about the postsynaptic cell, whether it is a thermoregulatory cell and if it possesses receptor sites for the drug in question.

Studies on the effects of central injections of putative neurotransmitters on thermoregulation go back to 1943 when von Euler (cited in Hellon, 1975) injected adrenaline (epinephrine) into the cerebral ventricles of rabbits. He observed a rise in body temperature and postulated that "...catecholamines, 5-HT (serotonin), or both may be mediators of activity of brainstem structures and...might also exert an influence on the setting mechanism of the body thermostat". Support for this view came from Feldberg and Myers (1963) who published results of intraventricular injections of epinephrine, noradrenaline (norepinephrine) and serotonin in the cat. They reported that epinephrine and norepinephrine decreased body temperature which had been previously raised by intravenricular injection of a pyrogen. 5-HT, on the other hand, caused a rise in body temperature either on its own or over and above a pyrogen-induced fever. With these findings, Feldberg and Myers (1963) proposed their "New Concept of Temperature Regulation" in which they suggested that normal body temperature is maintained by a delicate balance in the release of norepinehrine, epinephrine and serotonin in the hypothalamus. 
Since that time many more chemicals have been found to have thermoregulatory effects when injected centraliy. Some of the more reasonable chemicals include L-DOPA, dopamine, histamine and acetylchloline. Many mammals have been extensively studied for their responses to these and many other substances. Non-mammal ian vertebrates have not been studied as extensively and $f$ ish have been neglected save for two studies known to the author (Green and Lomax, 1976; Wollmuth et al., in press).

The results of these studies have not always been consistent and generalizations as to the effects of each particular drug injected even in the same species cannot easily be made. However, norepinephrine in most animals has been found to have a hypothermic effect (Bruinvels, 1979). This has has also been shown to be the case in goldfish where Wollmuth et al. (in press) showed that norepinephrine has a hypothermic effect when injected into the hy pothal amus.

Serotonin predominantly elicits a hyperthermic effect in cats, dogs and monkeys and a hypothermic effect in goats, oxen, mice, pigeons and chickens. Rabbits, rats and sheep show either response (Jacob and Girault, 1979) and rats sometimes show none (Crawshaw, 1972).

Acetylcholine and cholinergic substances when injected into the preoptic area/anterior hypothalamus (PO/AH), lead to increases in body temperature in monkeys and hamsters and 
decreases in guinea pigs (Crawshaw, 1979). Rabbits seem not to be affected whereas in cats both an increase and a decrease in temperature has been observed in the same animal. Studies on rats have produced hypothermia and hyperthermia (Crawshaw, 1979). In the fish chromus chromus, the acetylcholine agonist oxotremorine was found to mediate a hypothermic response (Green and Lomax, 1976) when administered through the gills via the water in which the fish was swimming. In the goldfish, acetylcholine has been shown to mediate both a hypothermic and a hyperthermic response depending on the site of injection within the hypothalamus and basal anterior forebrain (Wollmuth, personal communication).

Histamine, a neurotransmitter whose effects on thermoregulation have not been studied as extensively as the above drugs, causes a drop in body temperature when injected intrahypothalamically in both rats and mice (Lomax and Green, 1979). In the fish Chromus chromus aquatic histamine administration via the gills caused a hyperthermic response (Green and Lomax, 1976).

Early studies where dopamine was injected into the ventricles were found to cause a milder hypothermia than norepinephrine in the mouse when a larger dose was used (Brittain and Handley, 1967). These findings were explained by Cox (1979) as being due partly to the necessary diffusion through the ventricles so that the dopamine might 
have been inactivated before reaching its active site. Cox also mentions that effects due to a dopamine injection might be due to the biosynthesis of norepinephrine from the dopamine, since the latter is a precursor in the metabolic pathway to norepinephrine. Two pharmacological tools, according to Cox (1979), significantly accelerated the work on the involvement of dopamine in thermoregulation. One was apomorphine, a selective agonist of the dopamine receptor and the other was pimozide, a selective antagonist. Kruk (1972) found that apomorphine, injected into the lateral cerebral ventricle of the rat, caused an increase in tail skin temperature followed by a decrease in core temperature. Dopamine in a slightly higher dose caused the same changes, while pimozide pretreatment blocked both effects. As Cox (1979) points out, these findings indicate that dopamine is producing an effect in its own right and not via conversion into norepinephrine. What is also suggested by these findings is that dopamine receptor sites are mediating the thermoregulatiory response and not norepinephrine sites. This view is supported by the finding that the norepinephrine antagonist phentolamine does not block responses to dopamine (Cox and Lee, 1980). Dopamine studies in other animals have shown that hypothermia is the predominant response (Cox, 1979). The mouse, cat, pigeon and hen have all shown drops in core temperature after central dopamine injections. The baboon has shown no 
effect and the rabbit in several studies has consistently shown increased core body temperature after intraventricular injection of dopamine. This effect has been blocked by dopamine antagonists (Cox, 1979). Lomax and Green (1976) found that I-DOPA (the substrate for the synthesis of dopamine), when added to the water in which fish (chromus chromus) were swimming, elicited a hyperthermic response, though only in the middle one of the three doses used. This, however, at best only suggests that dopamine is linked to central temperature regulation in $\mathrm{fish}$. There is therefore a place for a more rigorous study of the role of dopamine in fish thermoregulation.

Evidence in support of a role for norepinephrine, serotonin, acetylcholine and dopamine in central thermoregulatory pathways has come from perfusion studies. These studies involve the sampling of extracellular fluid from an area of the brain while the animal is placed under different thermal loads. Myers and Chinn(1973), investigating cats, found that increasing the ambient temperature evoked a greater release of norepinephrine from the preoptic area. This release was restricted to the period of warming and immediately thereafter. Cooling the air around the cat to $10 \mathrm{C}$ did not evoke release of norepinephrine. Ruwe and Myers (1978) found that warming a cat by placing it in a $40 \mathrm{C}$ environment for 30 minutes evoked a release of dopamine from the preoptic area. There 
was a concomitant threefold increase of the cat's breathing rate. A similar study in the rhesus monkey (Myers and Beleslin, 1971), where serotonin levels were monitored found that cooling evoked an increased release of serotonin whereas heating either did not affect or inhibited serotonin release. Similar results were found for acetylcholine levels in another study on the rhesus monkey (Myers and Waller, 1973). The pattern of release of these substances is related to the ambient temperature and thermoregulatory responses of the animals in a way which would be predicted from the animals' responses to central injections of the substances. The findings of Myers and his colleagues therefore confirm injection study results with norepinephrine, serotonin, acetylcholine and dopamine. Electrophysiological evidence also exists for the participation of dopamine in central thermoregulatory mechanisms. Sweatman and Jell (1977) showed that dopamine, released by iontophoresis onto cold-sensitive neurons within the cat's hypothalamus, caused a decrease in the firing rate of these cells. As Lee et al. (1985) suggest, dopamine may elicit its effect by inhibition of cold-sensitive cells which in their turn inhibit heat production. The inhibited cold-sensitive cell might then disinhibit heat loss pathways in accordance with Hammel's model of the body temperature regulator given above. In a study by scott and Boulant (1984), where hypothalamic slices were perfused with 
dopamine, the activity of cold-sensitive neurons appeared to be reduced whereas that of cold-sensitive cells was increased. The excitation of warm-sensitive neurons would tend to activate heat loss pathways, again in accordance with Hammel's model, which would then lead to the type of behavior which has been observed after central dopamine injections.

To conclude, an overview will be given of the evidence in support of a physiological role for dopamine in thermoregulation:

1. Dopamine is present in the hypothalamus and more specifically, dopamine terminals have been described in the anterior hypothalamic and preoptic areas (Moore and Bloom, 1978). The preoptic area adjacent to the third ventricle is the most sensitive within the hypothalamus to the hypothermic effect of dopamine (Lee et all, 1985). 2. Dopamine and its agonists cause activation of heat loss mechanisms and subsequently hypothermia when injected into the preoptic area of the hypothalamus.

3. Effects, such as those mentioned under 2, are blocked by selective dopamine antagonists.

4. Dopamine release from the preoptic area is evoked when an animal is placed in a hot environment.

5. Dopamine applied to temperature-sensitive neurons leads to changes in their firing rates. 
This body of evidence is complete for the cat, but is more fragmented for other animals. 


\section{CHAPTER II}

\section{INTRODUCTION}

The hypothalamus of goldfish contains high levels of dopamine (Juorio, 1973) and a recent study (Kah et al.. 1984) has shown the presence of dopaminergic neurons within the nucleus preopticus periventricularis (NPP) of the hypothal amus of goldfish. Whether these neurons are involved in temperature regulation is not known. The present study, involving the microinjection of dopamine into the hypothalamus of the goldfish was undertaken to investigate whether dopamine can be considered to have a physiological role in temperature regulation in the goldfish. A microinjection method was favored, over methods affecting larger parts of the brain in an attempt to localize the site at which dopamine acts. 
CHAPTER III

MATERIALS AND METHODS

ANIMALS

Goldfish (Carassius auratus) weighing 40-80 g were kept at $25 \mathrm{C}$ with a 14L: 10D photoperiod prior to and during investigation and were fed daily on tropical fish food-flakes.

\section{SURG ICAL PROCEDURE}

Surgery on the $f$ ish was done under MS-222 anesthesia (initial concentration to anesthetize the animals: $0.28 \mathrm{~g} / 1$ water; later concentration to maintain anesthesia: $0.1 \mathrm{~g} / 1$ ). For the surgery, the fish was placed in a Baltimore Instruments stereotaxic apparatus modified for fish (after Peter and Gill, 1975). The gills of the fish were perfused with water containing the lower dose of anesthetic throughout the surgery. For placement of the guide cannula assembly (guide cannula was of 26 gauge stainless steel tubing) an aperture (approx. $4 \times 5 \mathrm{~mm}$ ) was made in the roof of the cranium. After the guide cannula assembly was stereotaxically placed in the desired location it was secured with dental acrylic to bone screws placed in the cranium. An indwelling stylette was placed within the guide 
cannula before the $f$ ish was placed in a recovery tank. Recovery from the effects of the anesthetic came within 15 minutes of the termination of surgery. Fish were not injected until two days after surgery. However, fish were placed in a themal gradient (see below) 24 hours after surgery to verify that their thermoregulatory behavior was normal.

\section{TEMPERATURE SELECTION MEASUREMENTS}

The effects on temperature selection of substances injected into the fish were measured in a horizontal thermal gradient. The gradient consisted of nine water-filled parallel lanes (width: $20 \mathrm{~cm}$, depth: $9 \mathrm{~cm}$, length:240cm) at the ends of which either hot or cold water was circulated in heat exchangers. This procedure produced a warm temperature at one end and a cold temperature at the other, with an almost linear gradation of temperatures in between. Temperatures at two positions in one lane were continually monitored and did not vary by more than $\pm 0.5 \mathrm{C}$ over any particular day. At the end of each day's work, a temperature profile for each lane was obtained. The range of temperatures for each lane was approximately 7-35 C.

The position of each fish within the gradient was monitored via a wide-angle video camera placed above the gradient. Lighting was diffuse and even over the area of the gradient. The image from the camera was digitized by an 
Oculus-2øø frame grabber and the position of each fish was recorded at 5 second intervals on an IBM PC XT. After recording was completed the temperature profile of each lane was utilized in combination with the position of each fish in each lane to produce a record of the water temperature chosen by each fish against time.

\section{INTRACRANIAL INJECTIONS}

Dopamine hydrochloride (Sigma) was dissolved in sterile $0.78 \mathrm{NaCl}$ (w:vol water) carrier. The injection volume was $\emptyset .2 \mu 1$ and the amounts of dopamine injected were $25,50,10 \emptyset$ and $250 \mathrm{ng}$. Control injections consisted of the carrier adjusted to the $\mathrm{pH}$ of the highest injection dose by the addition of $\mathrm{HCl}$. The dopamine antagonist Haloperidol (Sigma) was injected in the same volume of carrier as dopamine and at a dose of $250 \mathrm{ng}$.

On the day of injection the fish were placed in the gradient for $3 \emptyset$ minutes just prior to administration of the drug. During this time a recording was made of the thermoregulatory behavior of each fish which served as a baseline. To make the injections, each $f$ ish was placed in a restraint within the gradient at a position corresponding to its acclimation temperature. The restraint consisted of a cage with a trap door on its floor for easy release of the fish and an attached $5 \mu \mathrm{l}$ syringe. An injector cannula ( 33 gauge), connected to the syringe with PE tubing, was then 
positioned within the guide cannula. The injection was administered over a period of approximately 3 minutes after which time the PE tubing was clipped and sealed using hot forceps, and the fish released through the trap door. The selected temperature was then recorded for a period of 30 minutes. Each $f$ ish was injected a maximum of 5 times with a break of one day between each injection. Haloperidol injections were administered 10 minutes prior to dopamine through the same syringe. The haloperidol was kept separate from the dopamine by a $\emptyset .1 \mu l$ air-bubble.

\section{HISTOLOGY}

After investigation on a fish was completed it was anesthetized and its circulatory system was perfused with phosphate buffer ( $0.1 \mathrm{M}, \mathrm{pH}: 7.4)$ followed by glutaraldehyde solution (2.58 in the same phosphate buffer). Following the perfusion, $0.2 \mu l$ of Evan's blue dye was injected into the brain through the injection cannula. The brain was then dissected out and placed in fixative for 2-3 hours followed by phosphate buffer (as above) for 24 hours. The brain was finally embedded in egg yolk, fixed for 20 minutes in glutaraldehyde solution (as above) and sectioned. Sections $(4 \boxminus \mu m)$ were cut on a vibratome and stained using Richardson's stain.

The location of the injection site was determined by the tract left by the guide and injection cannulae. The 
site of the injection was taken to be the center of the tip of the injection cannula tract. Ventricular injections were indicated by the presence of dye in the ventricle with the rostro-caudal location determined by tissue damage from the guide cannula. The stereotaxic atlas of Peter and Gill (1975) was used as the reference in identification of the injection site.

\section{DATA ANALYSIS}

To evaluate the effect of an injections in fish, the Temperature Selection Index (TSI) has been established in our laboratory (Wollmuth et al., in press). This index incorporates both the magnitude and duration of post-injection changes in selected temperature into a single numerical value. To determine the TSI, the mean 30 minute pre-injection selected temperature is subtracted from each post-injection temperature (taken at 5 second intervals). Then, starting with the first post-injection observation, these differences are summed until the animal's selected temperature is within $2.5 \mathrm{C}$ of the pre-injection value for 4 consecutive minutes; differences occurring during this final 4 minute period are not included in the summed value. For the sake of convenience, this summed value is divided by 1000. As an example, if for a 10 minute period following an injection the temperatures selected were $10 \mathrm{C}$ below the pre-injection mean and then abruptly returned to 
pre-injection levels, the summed value would be -1200 (based on $12 \emptyset$ total total observations), and the TSI would be -1.2 . A post-injection temperature selection by a fish which was within $2.5 \mathrm{C}$ of the baseline pre-injection recording was not considered significant.

A Kruskal-Wallis one-way analysis of variance test was used to test for significant differences in the TSI after dopamine or control injections into highly effective sites. Non-parametric multiple comparisons by STP (Sokal and Rohlf, 1981) were also used to compare differences in the TSI after dopamine injections. Differences in TSI between animals injected with the dopamine antagonist, followed by $250 \mathrm{ng}$ of dopamine, and injection of dopamine $(250 \mathrm{ng})$ alone were determined by a Mann-Whitney test. In all cases a probability of less than $\emptyset . \emptyset 5$ was accepted as statistically significant. 
CHAPTER IV

\section{RESULTS}

In this study 45 fish were used and a total of 72 injections made. The effects of dopamine were found to be dependent on the dose and also on the site within the brain where the drug was injected.

All 20 injections in which dopamine was injected into the rostral NPP (rostral-caudal planes +1.7 to +1.5 , inclusive; stereotaxic atlas of Peter and Gill, 1975) caused the fish to select colder water. The effect was dose-dependent.

Injections rostral to the NPP (rostro-caudal planes +1.8 and +1.9 in the atlas of Peter and Gill) did not elicit any effects. One injection of a high dose (250 ng) dorsal to the rostral NPP (plane +1.7) produced a small decrease in selected temperature but smaller doses had no effect. Injections in the adjacent region lateral to the rostral NPP also caused small decreases in selected temperature at doses of 100 and $250 \mathrm{ng}$. No effect was seen with a $50 \mathrm{ng}$ dose in this region. A 100 ng injection more caudally in the NPP (plane +1.2) elicited no effect. Two injections (100 and $250 \mathrm{ng})$ into the ventricle adjacent to the rostral NPP were also without effect. 
Responses to injections of dopamine into the NPP were often immediate but always within the first two-minute period analyzed post-injection. Figure 2 shows the responses to two injections, of different doses. The duration of the response was greater with increased dose. The trace showing selected temperature following a control injection is given for comparison.

Figure 3 shows the results of injections of different doses of dopamine into the rostral NPP. Responses to dopamine injections into the rostral NPP were significantly different $(U=18.25 ; P<0.05 ; D F=4 ; F i g .3)$. Fish injected with 25,100 and 250 ng dopamine selected significantly lower temperatures than control-injected fish. Although the temperature selected by $f$ ish injected with $50 \mathrm{ng}$ dopamine tended to follow a similar pattern, no significant difference was found. This may be due to the small number of fish tested at this dose. Finally, the temperature selected by fish injected with 250 ng was significantly lower than that selected by $25 \mathrm{ng}$ injected $\mathrm{f}$ ish. Of the 6 control injections made, 3 were followed by no response. An increase in selected temperature was observed following two injections and a slight decrease by an other. All 6 control injections were done on fish which had previously responded with decreased selected temperature to dopamine. 
In all three cases tested, haloperidol pre-injection reduced or abolished the hypothermic effect of $250 \mathrm{ng}$ dopamine (The difference is significant at $P<\emptyset .05 ; \quad U=5.45$; see Fig. 3). Thus, haloperidol-pre-injected fish exhibited a selected temperature similar to control-injected fish.

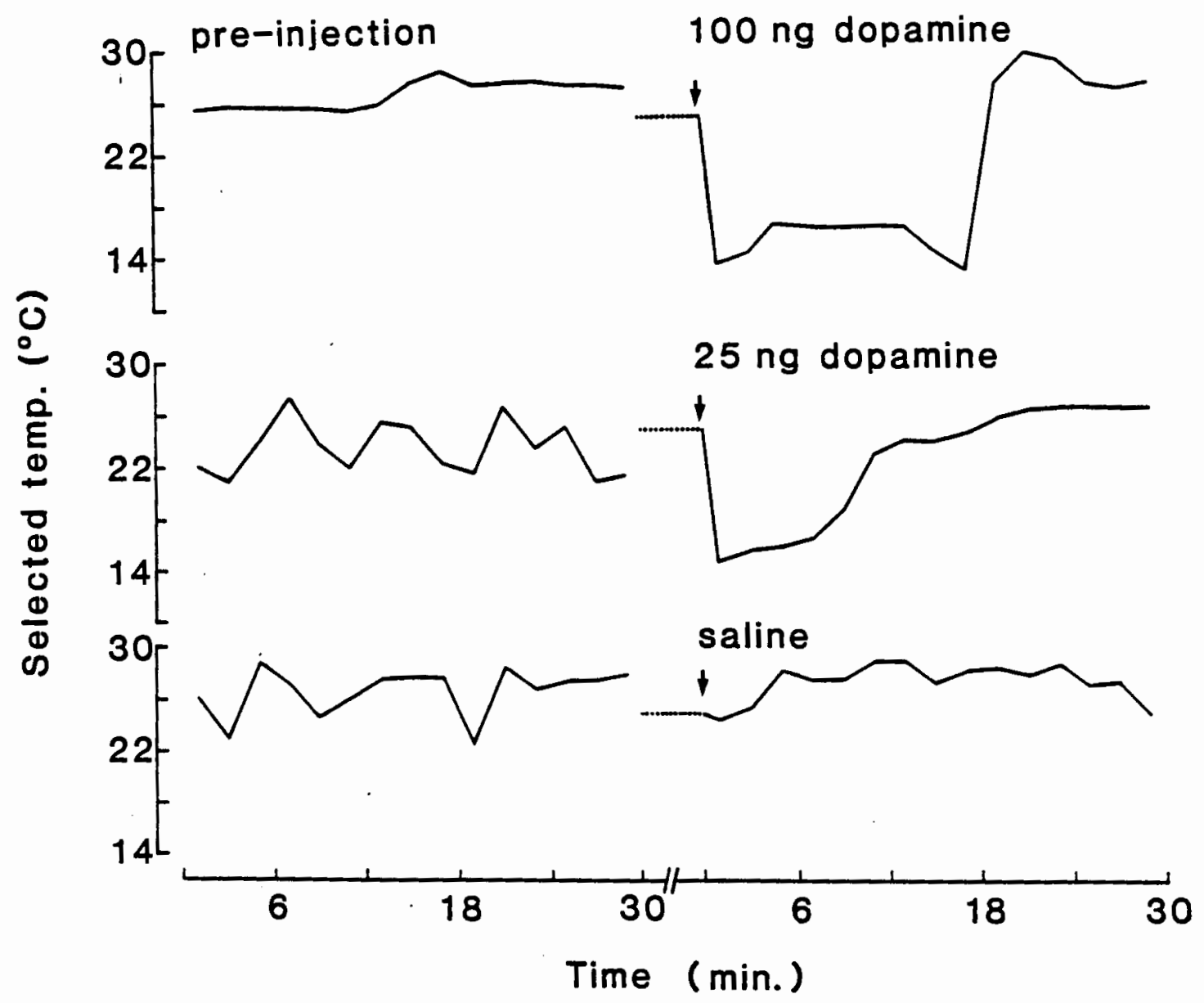

Figure 2. Pre- and post-injection selected temperature (at 2 minute intervals) for injections into the rostral nucleus preopticus periventricularis (NPP). The dotted lines indicate the 10 minute period when the animal was caught, the injector inserted, and the fish placed at $25 \mathrm{C}$ and allowed to settle down. The arrows indicate the time of injection. 


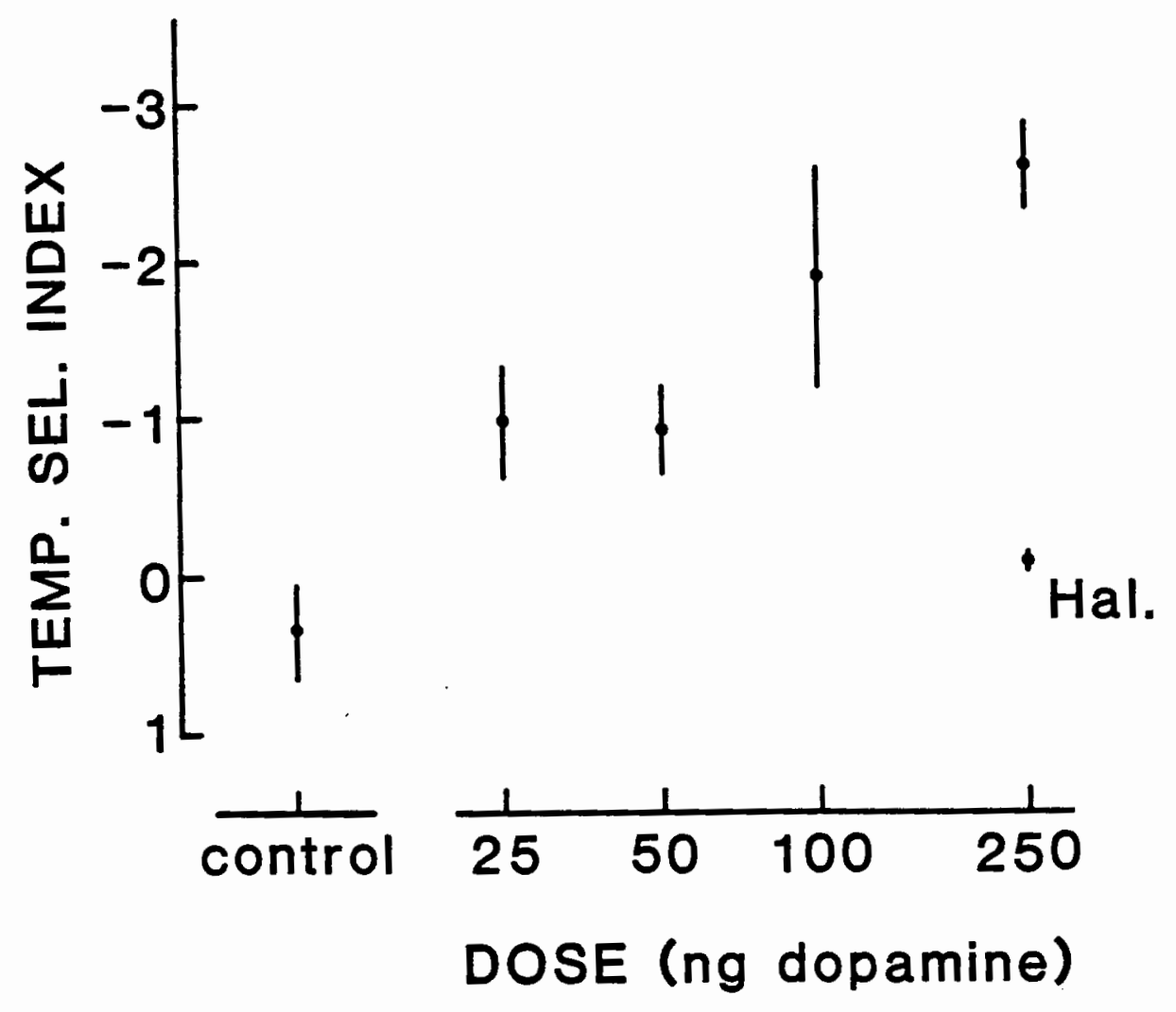

Figure 3. A semi-logarithmic dose-response curve for dopamine injections into the rostral NPP. Starting with the lowest dose, the number of injections at each dose was $5,4,5$ and 6 . Control injection data are included for comparison $(n=6)$. Hal, represents a haloperidol pretreatment $(n=3)$. Values shown are $\bar{X} \pm S E$ 
CHAPTER V

DISCUSSION

Dopamine, when injected centrally, has been shown to elicit a drop in body temperature in most animals studied (Cox, 1979; Lee et al., 1985). The present study has shown that intrahypothalamic injection of dopamine has an equivalent effect in the goldfish since these fish selected colder water after being treated with this putative neurotransmitter. Green and Lomax (1976) found that L-DOPA when administered through the gills of the fish chromus chromus caused a hyperthermic response in the middle dose of the three doses used. This result might represent the action of L-DOPA or dopamine synthesized from it on dopaminergic receptors in central thermoregulatory pathways. If this is the case the different response of chromus from that of goldfish might represent a species difference. The absence of a dose-dependent effect of L-DOPA administration in this fish would tend to cast doubt on the validity of the results obtained and might suggest that the response seen was only an artifact.

As in the cat (Ruwe and Myers, 1978) and the rat (Cox and Lee, 1980) a specific region within the hypothalamus of the goldfish appears to be maximally sensitive to the 
hypothermic effect of dopamine. For the cat and rat this sensitive area is the part of the preoptic area adjacent to the third ventricle (Lee et al, 1985). The rostral part of the nucleus preopticus periventricularis (NPP) is the sensitive site for dopamine injections in goldfish. Previously, it was shown (Nelson and Prosser, 1979) that lesions in the general vicinity of the NPP of goldfish lead to deficits in thermoregulation. The sensitive site for dopamine action is within the region ablated by Nelson and Prosser (1979). Since this area was shown to be essential for thermoregulation in the goldfish the action of dopamine would therefore appear to be mediated via the thermoregulatory neurons in this region.

The rostral NPP is also the part of the goldfish hypothalamus which is most sensitive in mediating a hypothermic response after intrahypothalamic injections of norepinephrine (Wollmuth et al., in press). Since dopamine is the immediate precursor in the biosynthesis of of norepinephrine then, as Cox (1979) has noted, dopamine might act via conversion to norepinephrine. The fact that haloperidol, a specific antagonist at the dopamine receptor, blocked the action of dopamine, argues against a norepinephrine mediated response. Instead, the haloperidol inhibition supports the view that dopamine is acting through its own receptors in the thermoregulatory pathway. This view is supported by the finding (Kruk, 1972) that pimozide, 
another dopamine antagonist, blocks the effects of dopamine but not of norepinephrine in the rat. Further evidence in support of a dopamine mediated hypothermia, at least in rats, is offered by Cox and Lee (1980). These investigators injected 6-hydroxydopamine bilaterally into the hypothalamus after a systemic administration of desipramine. This combined treatment destroys only dopaminergic and not noradrenergic nerve terminals (Cox and Lee, 1980). The long term results expected from such a treatment would be a deficit in the ability of the animal to activate heat loss mechanisms, usually activated by central dopamine injections. This was indeed found to be the case when such rats were placed under a heat load; vasodilation in the tail skin (the common response to central dopamine injection) was inhibited and core body temperature rose.

If dopamine is released from neurons in the NPP in the mediation of thermoregulatory behavior then it should be possible to detect its presence in the region. Juorio (1973) reports the presence of dopamine in the goldfish hypothalamus in higher levels than other catecholamines. Kah et al., (1984) report the presence of dopamine-containing cell bodies in the NPP and fibers leading caudally from this site to the pituitary. It is tempting to suggest that these cells in addition to mediating a neuroendocrine role (which Kah et al. suggest), are also involved in thermoregulation. These investigators 
do not mention the presence of dopaminergic terminals within the NPP which would, if present, indicate that this substance is released within this area. It is possible, however, that the techniques used by these investigators were not able to demonstrate the presence of terminals. If there are dopaminergic receptors in the thermoregulatory pathway, then on what type of cells are they located? Since the cells being affected by the injections are within the hypothalamus then the receptors might be located on the cells comprising the controlling center of temperature regulation or possibly on efferent thermoregulatory neurons. If the activity of either of these neuronal systems is affected by a drug, the result would be the manifestation of some thermoregulatory behavior followed by a change in body temperature.

There is evidence to support the view that the thermoregulatory controlling center neurons of the goldfish are in the NPP. Nelson and Prosser (1979) bilaterally ablated the NPP of goldfish and found that the fish could no longer thermoregulate. The absence of normal thermoregulatory behavior would indicate that the critical controlling centers were destroyed by the treatment. Whether neurons in the effector pathway are located in the NPP is not clear, but it is conceivable that they are present and therefore might be affected by drug treatments in this area. 
Green and Lomax (1976), in their study of drug effects on temperature regulation in the fish chromus chromus, feel that the drugs, which were administered through the gills and so potentially affected not just the hypothal amus but other sensitive regions too, influence the preferred or set temperature of the $f$ ish. In other words, they suggest that the controlling centers are being affected by the drug treatment. They do not, however, offer any support for this view. Since the precise site of action of drugs affecting thermoregulation, even within the hypothalamus, is not known, the author believes that it is not possible to make conclusions on this point. Neuroanatomical data of thermoregulatory pathways within this region will be needed, coupled with an understanding of the neurochemistry of the cells involved, before conclusions can be drawn on which cell group (controlling center or effector pathway) is being affected by the drug treatment.

Only a partial answer can therefore be given to the question as to the location of dopaminergic receptors. Within the controlling centers dopamine could act by reducing the activity of cold-sensitive neurons as is suggested by Sweatman and Jell (1977) for the cat. Alternatively, or in addition to its action on cold-sensitive neurons, dopamine might cause excitation of warm-sensitive neurons as is suggested by scott and Boulant's (1984) study. In either case, in accordance with 
Hammel's model (see fig. 1), the treatment would lead to increased heat loss and inhibition of heat production or, in ectotherms, a choice of a cooler environment. Whether the receptors for dopamine would be on the actual hot or cold sensitive neurons or on some intermediate neurons acting on these two types of neuron is another question which needs to be answered. Receptors for dopamine, however, could, conceivably be located on neurons in the effector pathway mediating cooling of the body. These cell bodies would have to be located within the area affected by the dopamine injection - the rostral NPP in goldfish.

The results of this study offer evidence for a physiological role for dopamine in central thermoregulation in goldfish. Further, this study localizes the effect of dopamine to the NPP. These findings contribute to the body of information suggesting that dopamine participates in the neurological mechanisms that control behavioral temperature regulation in vertebrates. 


\section{REFERENCES}

Brittain, R.T. \& Handley, S.L. (1967) . Temperature changes Produced by the Injection of Catecholamines and 5-hydroxytryptamine into the Cerebral Ventricles of the Conscious Mouse. I. Physiol. 192: 805-813.

Bruinvels, J. (1979). Norepinephrine. In: Body Temperature Eds. P. Lomax and E. Schönbaum. Marcel Dekker.

Cox, B. (1979) . Dopamine. In: Body Temperature. Eds. P. Lomax and E. Schönbaum. Marcel Dekker.

Cox, B. \& Lee, T.F. (1980). Forther Evidence for a Physiological Role for Hypothalamic Dopamine in Thermoregulation in the Rat. I. Physiol. 300: 7+17.

Crawshaw, L.I. (1972) . Effects of Intracerebral 5-hydrxytryptamine Injection on Thermregulation in Rat. Physiol. Beh. 2: 133-140.

Crawshaw, I.I. (1979). Acetylcholine. In: Body Temperature. Eds. P. Lomax and E. Schönbaum. Marcel Dekker.

Crawshaw, L.I., Grahn, D., Wollmuth, I. \& Simpson, L. (1985) Central Nervous Regulation of Body Temperature in Vertebrates: Comparative Aspects. Pharmac. Ther. 30: $19-30$.

Feldberg, W. \& Myers, R.D. (1963). A New Concept of Temperature Regulation by Amines in the Hypothalamus. Nature 20l: 1325 .

Green, M.D. \& Lomax, P. (1976). Behavioural Thermoregulation and Neuroamines in Fish (Chromus chromus). I. Thermal Biole 1: 237-240.

Hammel, H.T. (1968). Regulation of Internal Body Temperature. Ann. Rey. Physiol. 30: 641-710.

Hammel, H.T., Crawshaw, L.I. \& Cabanac, H.P. (1973). The Activation of Behavioral Responses in the Regulation of Body Temperature of Vertebrates. The Pharmacology of Thermoregulation. Eds. E. Schonbaum and P. Lomax. Karger. 
Hellon, R.F. (1975) . Monoamines, Pyrogens and Cations: Their Actions on Central Control of Body Temperature. Pharmacol. Rey. 26(4): 289-321.

Jacob, J.J. \& Girault, J.-M.T. (1979) . 5-Hydroxytryptamine. In: Body Temperature. Eds. P. Lomax and E. Schonbaum. Marcel Dekker.

Juorio, A.V. (1973). The Distribution of Catecholamines in the Hypothalamus and other Brain Areas of some Lower Vertebrates. I. Neurochem. 20: 641-645.

Kah, O., Chambolle, P., Thibault, J. \& Geffard, M. (1984). Existence of Dopaminergic Neurons in the Preoptic Region of the Goldfish. Neurosci. Lett. 48: 293-298.

Landgren, S. (1970). Projections from Thermoreceptors into the Somatosensory System of the Cat's Brain. In: Physiological and Behavioral Temperature Regulation. Eds. Hardy, J.D., Gagge, A.P. and Stolwijk, J.A.J. Charles Thomas. pp. 454-462.

Kruk, Z.L. (1972). The Effect of Drugs Acting on Dopamine Receptors on the Body Temperature of the Rat. Life Sci. 11: 845-850.

Lee, T.F., Mora, F. \& Myers, R.D. (1985). Dopamine and Thermoregulation: An Evaluation With special Reference to Dopaminergic Pathways. Neurosci. Biobeh. Rey. 2: 589-598.

Lomax, P. \& Green, M.D. (1979) . Histamine. In: Body Temperature. Eds. P. Lomax and E. Schönbaum. Marcel Dekker.

Moore, R.Y. \& Bloom, F.E. (1978). Central Catecholamine Neuron Systems: Anatomy and Physiology of the Dopamine Systems. Ann. Rey. Neurosci. 1: 129-169.

Myers, R.D. \& Beleslin, D.B. (1971). Changes in serotonin Release in Hypothalamus During Cooling of Warming of the Monkey. Am. I. Physiel. 220: 1746-1754.

Myers, R.D. \& Chinn, C. (1973). Evoked Release of Hypothalamic Norepinephrine during Thermoregulation in the cat. Am. I. Physiol. 224: 230-236.

Myers, R.D. \& Waller, M.B. (1973). Defferential Release of Acetylcholine from the Hypothalamus and Mesencephalon of the Monkey during Thermoregulation. I. Physiol. 230: 273-293. 
Nakay ama, T. Eisenman, J.S. \& Hardy, J.D. (1961) . Single Unit Activity of Anterior Hypothalamus during Local Heating. Science 134: 560-561.

Nelson, D.O. \& Prosser, C.L. (1979). Effect of Preoptic Lesions on Behavioral Thermoregulation of Green Sunfish, Lepomis cyanellus, and of Goldfish, Carassius auratus. I. Comp. Physiol. 129: 193-197.

Nelson, D.O. \& Prosser, C.I. (1981). Temperature-sensitive Neurons in the Preoptic Region of Sunfish. Am. I. Physiol. 241: R259-R263.

Peter, R.E. \& Gill, V.E. (1975). A Stereotaxic Atlas and Technique for Forebrain Nuclei of the Goldfish Carassius auratus. J. Comp. Neurol. 159: 69-102.

Ruwe, W.D. \& Myers, R.D. (1978). Dopamine in the Hypothalamus of the Cat: Pharmacological Characterization and Push-Pull Perfusion Analysis of Sites Mediating Hypothermia. Pharmacol. Biochem. Beh. 2: 65-80.

Scott, N.R. \& Boulant, J.A. (1984). Dopamine Effects on Thermosensitive Neurons in Bypothalamic tissue slices. Brain Res. 306: 157-163.

Sokal, R.R. \& Rohlf, F.J. (1981). Biometry 2nd Edition. Freeman.

Sweatman, P. \& Jell, R.M. (1977). Dopamine and Histamine Sensitivity of Rostral Hypothalamic Neurones in the Cat: Possible Involvement in Thermoregulation. Brain Res. 127: 173-178.

Wollmuth, L.P., Crawshaw, L.I. \& Panayiotides-Djaferis, H. Am. I. Physiol. (in press) 